\title{
ФОЛЬКЛОР
}

\author{
Е.А. Тинякова
}

\section{КАК ФОЛЬКЛОР МОЖЕТ СТАТЬ ИСТОЧНИКОМ ИСТОРИЧЕСКИХ ИССЛЕДОВАНИЙ}

Аннотация. Объектом исследования настоящей статьи являются повествовательные функции форм русской народной традиционной культуры, и прежде всего связанных с устным словом или вокальным творчеством, а предмет исследования - историческое содержание повествовательного аспекта русской народной традиционной культуры. Цель настоящей статьи - представить историческое содержание русской традиционной культуры как вспомогательную историческую дисциплину, которая поможет преподавать отечественную историю более иллюстративно. Русская народная словесная культура представлена как исторический текст. Как пример такого подхода было выбрано крестьянское восстание Е. Пугачёва. В статье представлен диалог художественно метода в познании в диалоге с научным, а именно историческим. Новое в представленном исследовании - рассмотрение фольклора русской традиционной культуры как исторического текста в массовом народном сознании. Научный подход влечёт за собой новую методику: обучающимся предлагается составить исторический текст путём выборки деталей и фактов, зафиксированных в народных преданиях, народных песнях и других формах народного творчества. Историческое знание должно обязательно сопровождаться самостоятельным поиском.

Ключевые слова: история, традиционная культура, устные формы, фольклор, массовое сознание, документальность, мифологизация, интерпретация, вспомогательная дисциплина, исследование.

Abstract. The object of the present research is the narrative functions of the forms of Russian traditional folklore culture, most of all, oral forms and vocal art. The subject of the research is the historical content of the narrative aspect of Russian traditional folklore culture. The purpose of the article is to present the historical content of Russian folklore culture as an additional historical discipline among other supporting historical disciplines such as genealogy, toponymy, heraldry etc. Historical content, kept in traditional culture, helps to make teaching Russian history more illusrative, besides learners are proposed to choose details and facts, present in folk tales and legends, folk songs and other forms of traditional culture and build up historic texts themselves, hence it is just the beginning of research approach to historic information. Russian foklore culture is represented as a historical text. Emelian Pugachev's revolt is given as the case study. Under contemporary educational process, strongly dependent on internet resources, this approach to collect details of historic facts in forms of traditional culture is very cognitively activating, because historic knowledge itself is vertical not horizontal. The novelty of the research is caused by the fact that the author views Russian folklore as a historical text represented in the nation's collective consciousness. The new scientific approach implies a new research method. History, kept in forms of folk culture, presents mass historic conscience, polished through a lot of various opinions and confirmed in the course of history pacing. Folk culture is the treasury of historic moods that accompanied events, it follows the 'iceberg' principle: little is on the surface and much is to be discovered and guessed.

Key words: history, folklore, oral forms, traditional culture, mass (collective) consciousness, documentation, mythologization, interpretation, additional discipline, research.

Ц ель представленного исследования - рассмотреть информационный статус знания по истории России, в основном включённого в образовательное пространство современной школы и среднего профессионального образования, и дать его социальную проекцию для подрастающего поколения, найти образовательные резервы для повышения познавательного уровня и социально-политического качества в формировании исторического менталитета.
Поставленная цель исследования продиктована особенностями развития исторической науки и исторического знания в системе образования после перестройки: раскрылись ранее не использованные резервы исторической информации, большей частью архивного плана и ещё консервативно хранящиеся у носителей памяти исторических событий, утверждение демократической концепции государства породило множество точек зрения, дополняющих и кардинально меняющих 
представления. Эта ситуация сказалась на учебных материалах по истории России для средней общеобразовательной школы и средних профессиональных учебных заведениях, безусловно и вузовских учебниках. Точка зрения автора настоящего исследования заключается в том, что сейчас возникла необходимость привлечения к «генеральному» потоку исторической информации в учебниках вспомогательных исторических дисциплин, которые менее зависели от документальной, архивной истории, более ориентированы на массовое историческое сознание. Автор представляет в статье историческое содержание русской народной традиционной культуры как вспомогательную историческую дисциплину среди других: этнография, сфрагистика, историческая география или топонимика, геральдика, историческая генеалогия, бонистика, вексиллология, фалеристика, медальерика, глиптика и другие. В предлагаемом подходе к сопровождению исторического знания из учебников методический акцент делается на самостоятельный поиск исторических фактов и деталей, дополняющих обязательную квоту исторического знания из учебника. Более того, с познавательной точки зрения историческое знание обязательно требует самостоятельного поиска, так как с информационной точки зрения оно имеет вертикальную, а не горизонтальную структуру. Как пример такого методического подхода было выбрано крестьянское восстание Е. Пугачёва.

Обратимся к историческому контексту, который подвёл русский народ к крестьянской войне 17731775 гг. под предводительством Емельяна Пугачёва. По воспоминаниям современников народ был настолько нищ, что едва ли был «виден в нём образ человеческий» $[5$, с. 315-316]. Волнения крестьян и городской бедноты учащались, и для наведения порядка призывалась полиция и войска. На волне крестьянского недовольства появляется борец против «неправедных людей» - Емельян Пугачёв.

«Добрый молодец Емельян Пугач...

Со князьями, со боярами не кланяется,

К астраханскому губернатору и под лад не йдёт...» $[6$, с. 90].

В народных преданиях сохранился образ Пугачева, его живой, весёлый, смелый, энергичный, находчивый характер. До нас дошла память о его любимой песне «Не шуми, ты мати, зелёная дубравушка». Природный фон повествования в русских народных исторических песнях восходит к высшей божественной справедливости, растворённой в природе. Это особенность понимания Бога в народном сознании, не облачённая в литургию служб в церкви. Яицкие казаки сложили песню о своём вожде и называли его «государем»; легенды и сказы о народном вожде переходили из уст в уста - народ его поддерживал словом: «красное солнышко», «Емельян-батюшка», «радеющий за мужиков», «богатырь», «атаман», «добрый молодец», а в последних песнях Пугачёва называли «звёздочкой», когда он сидел в тюрьме под стражей. До нас дошла поговорка пугачёвцев: «Ходи браво, гляди прямо, говори, что вольны мы».

В исторической песне говорится о том, что в янваpe 1772 г. на реке Яике восстало беднейшее крестьянство: «Яичкие казаки-бунтовщики ... генерала они убили, в том их немало судили...они сердце разъяря, пошли искать себе царя» [2, с. 97]. Ещё одна песня «Что пониже было города Саратова» $[1$, с. 125-126]. Она была записана Данилом Кашиным в 1930-х гг. XIX в.:

Что пониже было города Саратова,

А повыше было города Царицына,

Выплывают ли стружочки есаульские.

На стружочках тех сидят гребцы бурлацкие:

Все бурлаки, все молодчики заволжские.

Губернатора ждали Астраханского.

Буйну голову срубили с губернатора, Они бросили головку в Волгу-Матушку.

Не простили казаки губернатору, что он «строгонек был»:

Ты ведь бил нас, ты губил нас, в ссылку ссылывал, На воротах жён, детей наших расстреливал [1, с. $125-126]$.

Пугачёвский бунт начался с жестокой мести за тяжёлые условия жизни и карательные меры. Постепенно собирались вокруг Пугачёва недовольные, желающие искать справедливости, до крайней степени обозлённые на жестокости крепостного права. События, когда Пугачёв обнародовал первый манифест 17 сентября 1773 г. [2, с. 103] отразилось в народной песне:

... С большой силой собрался,

Под Яик поднялся.

Под Яик подходил,

Батальицу сочинил.

Они начали палить.

Силу - армию валить.

В начале крестьянской войны Пугачёв собрал войско, которое могло противостоять царской армии. В другой исторической песне «Нас пугали Пугачём» мы узнаем, как складывалось крестьянское войско Пугачёва [1, с. 122-124]:

- «государь нас бил сплеча» - сильное противостояние царской армии; 
- «а попов всех на костры»- в песне говорится, как Пугачёв призвал к себе бойцов, оттянув их «от икон и крестов»; здесь проявилось безбожье менталитета его крестьянской армии;

- в войске Пугачёва были разные национальности: «тут ватага собралась, да, и киргизы и татары, и все вместе рать пошла», в песнях также упоминаются калмыки.

Оренбург был намечен стратегической целью, форпостом в движении крестьянской армии Пугачёва; крестьянский вождь наметил этот город как противостояние столице. Отсюда он планировал, укрепив армию, двинуться на столицу:

\section{Ой, да ты, батюшка}

Вот и Оренбург-город!

Ой! Про тебя-то идёт вот слава добрая

[1, c. $122-124]$.

Однако накапливая силы, пугачёвское войско не учло наращивания мощи царской армией. Царская армия держала войско Пугачёва под пристальным оком и истощала его силы [4, с. 191-192]. Компетентность исторического метода русской традиционной культуры отражена в народной песне, где указывается стратегическая ошибка Пугачёва $[6$, с. 96, 98]:

\section{Из России тьма солдат}

На Урал идут, Пугача возьмут,

Полонят его и всю армию.

Твоему казаку снимут голову,

Снимут голову, пустят по воду...

И всё же главная причина поражения войска Пугачева было предательство из его окружения [6, c. 96, 98]. Когда Пугачёва схватили, то сама императрица Екатерина II следила за тем, чтобы казнь крестьянского вождя состоялась и при том публично. Когда осуждённых везли на место казни, погода в Москве была хмурая, собравшийся народ даже не прореагировал на торжественный въезд Екатерины II: «...во время всей церемонии со стороны народа не было возгласов или вообще какого бы то ни было выражения хотя бы малейшего удовольствия. Посещение императрицы далеко неприятно ... народу» [4, с. 191-192]. Интересно привести одно сравнение. Когда Л.Н. Толстой накануне своей свадьбы с С.А. Берс был во Франции, он случайно увидел гильотину. Он был настолько шокирован, что потом еле-еле отошёл от своего впечатления во время путешествия по Швейцарии и созерцания швейцарской природы. А Екатерина II сама жаждала созерцать казнь и всячески предостерегала, чтобы Пугачёв и другие осуждённые не умерли в тюрьме. К сожалению, пока не появилось ни одного исторического исследования о жестокости царской власти, тогда как линия кровавых казней проходит через царскую династию. Поэтому вполне справедливо критиковать монархическую политическую позицию за историческую некомпетентность. Обратимся к одному из исторических источников, где приводятся подробности казни руководителей крестьянской войны 1773-1775 гг. «Стоя на коленях, он (Пугачёв) ответил на заготовленные вопросы о признании своих преступлений, после чего суд принял решение: «Емельку Пугачёва четвертовать, голову воткнуть на кол, части тела разнести по четырём частям города и положить на колёса, а после на тех местах сжечь». Вместе с Пугачёвым к четвертованию был приговорён и Афанасий Перфильев. Ещё три человека - М. Шигаев, Т. Подуров и В. Торнов были приговорены к повешению, а И. Зарубин к отсечению головы, причём Чику-Зарубина должны были казнить в Уфе, осаду которой он вёл. Приговор был приведён в исполнение 10 (21) января 1775 на Болотной площади» [7]. Ведь Болотная площадь и в наши дни остаётся местом выражения социальной справедливости. Поэтому при современной активизации православной церкви в понимании русской истории и открытии исторических источников, которые были в ведении православной церкви, требуется глубже войти в трагизм русской истории с молитвой. Новомученики, погибшие во время сталинских репрессий, уже вошли в общерусский сонм мучеников. Однако духовная работа за мучеников в дореволюционный период ещё предстоит.

Существенное отличие исторического повествования в русской традиционной культуре в том, что у него всегда был христианский оттенок. За справедливостью народ обращался в природе, где, по мнению народа, был растворён объективный смысл. Как было отмечено выше, силы пугачевского войска отличались атеистической позицией, потому что священнослужители свято чтили богопомазание царской власти, а где же тогда простому народу было искать справедливости? Однако накануне казни Пугачёв крестился на соборы Москвы и повторял: «Прости, народ православный». Здесь нет противоречия: в глубине души Пугачёв был всё же православным, но столкновение крестьянской армии и царской на линии мести было настолько воинственным, что отошли в сторону какие-либо христианские позиции. Этот вывод показательно существен в настоящем пересмотре революции 1917 г.: противостоявшие силы «белой» и «красной» армий после почти векового срока соединяются в истоке. А теперь обратимся к фольклору, правда уже авторскому в конце XIX в. и начале XX в., в известных революционных песнях не было резкого разделения на две противостоящие силы. 
Вернёмся к анализу исторического события, зафиксированного в народной традиционной культуре. Оренбург известен как «пугачёвская столица», поэтому там хранится много устных преданий, рассказов, некоторые из них документально не достоверны, но устное их существование и хранение - дань историческому событию. Только в устных формах русской традиционной культуры можно встретить «омифилогизированную историю»: исторические события настолько глубоко вошли в память народа, что уже различие между документальностью и вымышленным фактом стерлось.

Этот тип истории можно определить как «духовный памятник» историческому событию, который хранит исторические настроения. Оренбургские краеведы до сих пор ходят по пугачёвским тропам: Сентова слобода (сейчас село Татарская каргала), Пугачёвская пещера в полутора километрах юго-западнее посёлка Ленина, по следам Пушкинского предания в Бердах, в Сакмарском районе, ищут клад у озера Сидурихи, Гребенской горы. Создаются легенды о Пугачёвском кургане у села Павловка на левом берегу Урала. В 1890 г. архивариус Оренбургского казачьего войска Н.К. Бухарин записал легенду со слов старых казаков о неком силаче Лямзине из поселка Хабарный, который дожил до 125 лет. Этот силач был прототипом Е. Пугачева [3, с. 195].

После подавления крестьянского восстания всякое упоминание о Е. Пугачёве было грозно запрещено, поэтому краеведам можно обращать внимание на такого типа легенды. В историческом методе русской традиционной культуры такие полумифологизированные легенды служат примером обхода цензуры массовым сознанием. Несмотря на то, что народная память хранит образ Пугачева в очень большом пространстве, но населённых пунктов на карте России немного по причинам былых исторических запретов. Хорошо известен город Пугачёв в Саратовской области, есть также посёлок Пугачёвский в Оренбургской области. Были вре́менные названия, например, город Николаевск в Заволжье назывался Пугачёв, станция Иловайская и поселок того же типа по железной дороге из Донбасса в Таганрог и Ростовна-Дону временно носили имя народного крестьянского вождя. В Котельниковском районе Волгоградской области есть станица Пугачёвская, она была центром Пугачёвского сельского поселения, а в 1773-1775 гг. была казацкой станицей Зимовейской Войска Донского. Фамилия Пугачёва покрывала героизм Чапаева (первый полк был имени Емельяна Пугачёва, впоследствии Пугачевская бригада), а во время Великой отечественной войны имя Пугачёва использовалось как боевой призыв, среди партизан и антифашистов за рубежом.
Имя народного героя сохранилось в названиях улиц Москвы и Петербурга; в Сергиево-Посадском районе Московской области близко к поселению Семхоз есть улица Пугачёва; в столичных и краевых музеях бережно хранятся реликвии пугачёвских времен (сохранился документ с его личной подписью). Память о пугачёвском восстании стало темой литературных произведений, картин художников, музыкальных произведений [7]. Тема пугачёвского восстания очень актуальная для современных взглядов и их пересмотру на октябрьскую революцию 1917 г. Историки ищут теоретическую основу разработки стратегии революции большевиками в марксистской теории о пролетариате: движущимися силами революции были пролетариат и беднейшее крестьянство по теории В.И. Ленина, однако в совершении революции более сказалась традиция русской истории: революционные события 1917 г. стали апогеем протеста бедных и беднейших слоёв населения России по причине их запредельного к человеческим возможностям существования.

В историческом содержании русской народной традиционной культуры сохранилось обширное историческое описание такого крупного исторического события как бунт под предводительством Е. Пугачёва. В фольклорных материалах, и прежде всего песнях, выстраивается чёткая цепь событий: причина крестьянской войны, как сложилась организация войска Пугачёва, исторический путь пугачёвцев, описание характера Пугачёва как военного лидера, а также быт его войска, разгром крестьянского войска и его причины, и трагический конец народного защитника. Таким образом, историческое содержание фольклора является ценным источником для исторических исследований. Более того, от содержания этого исторического источника тянутся выводы к последующим историческим периодам.

Пример использования форм русской народной традиционной культуры как исторического источника может быть очень благотворен при изучении истории, и прежде всего в средней общеобразовательной школе и средних профессиональных учебных заведениях. Во-первых, изучая исторические песни, легенды, сказания ученики восстанавливают и собирают по деталям исторические контексты, а это уже начало исследовательской ступени в познании и изучении материала. При росте современной активности школьников им надо открывать пути самостоятельного приобретения знаний, не только уже готового материала из учебника. Во-вторых, этот материал очень иллюстративен. В-третьих, он лучше расположен к запоминанию. В-четвёртых, исторические события и личности показаны в главных штрихах и деталях, отсортированных народным сознанием. Итак, предложение к учебникам 
по истории: делать приложение «Материалы для чтения», где бы были собраны исторические песни, легенды, изучая которые обучающиеся могли бы сравнивать извлечённый материал с содержанием учебника. Это может стать исследовательским подходом к изучению истории.

Исторический материал русской народной традиционной культуры полезен и для высоких академических исторических изысканий, так как он включает массовое сознание и предостерегает от авторских перекосов в интерпретации исторических событий, а при внимательном аналитическом изучении может навести и на углубление исторических поисков. Вернёмся опять к крестьянскому восстанию Е. Пугачёва.

Манифест Пугачёва был подготовлен на разных языках, в том числе и арабском. Это заставляет думать, что у войска Пугачёва были контакты, требующие арабского языка. Этот штрих требует поиска, но может так и остаться вопросом, если документальные свидетельства не будут найдены. Но в историческом поиске нельзя всегда стремиться к чёткому ответу, остающиеся вопросы могут сами остаться неотвеченными. Выше были приведены примеры «омифологизированной» истории, которая хранится в народных легендах.

Недостаток в документальности всё же не должен привести к её списыванию со счетов истории. Народные легенды ценны тем, что они хранят исторические настроения, как бы «духовное видение» исторических фактов и событий массовым сознанием рядовых участников. Если в формах искусства живописи, музыке, скульптуре - исторические события и личности отходят от документальности по дороге метафоры и художественного творчества, то в русской народной традиционной культуре документальность больше проявляется в недоговорённости, спрятанности исторического факта по прин- ципу айсберга, поэтому она служит историческому изучению и исследованию.

Предложенный методический подход к преподаванию истории России, а также исследованию исторического контекста, соединяется со всё более набирающей силу историей повседневности. В истории повседневности большое значение имеет изучение дневников, писем, то есть показывается, как регистрировалась история как можно большим числом участников исторических событий. История повседневности как особая историческая дисциплина утвердилась большей частью на материалах Великой отечественной войны, частично Первой мировой войны. А если проникать вглубь истории - XIX в., XVIII в., XVII в., то такую же роль могут сыграть источники, взятые из форм словесной русской народной традиционной культуры.

Отличие истории повседневности и исторического содержания русской народной традиционной культуры в том, что первая даёт более индивидуализированные источники, а в формах народной культуры фрагменты исторической информации более обобщённые. В формах русской народной традиционной культуры больше раздумывания, оценки событий и личностей, даже критичности, а в источниках истории повседневности больше представляется хроникально индивидуальное видение исторического факта.

Обе линии дополняющего изучения исторического материала - русская народная традиционная культура и история повседневности - представляют ту широкую почву исторической науки, на которой утверждаются авторские концепции и подходы учёных-историков, и они служат своеобразной формой проверки предлагаемых авторских концепций на крепость: как они утверждаются в «народной почве истории».

\section{Список литературы:}

1. Бачинская Н., Попова Т. Русское народное музыкальное творчество: хрестоматия. Изд. 4-ое. М.: Музыка, 1974. C. $122-126$

2. Крестьянская война в России в 1773-1775 годах. Восстание Пугачёва. Т. 2. Л., 1966. С. 97, 103.

3. Под знамёнами Пугачёва. Челябинск: Южно-уральское книжное изд-во, 1973. 195 с.

4. Рознер И. Казачество в крестьянской войне 1773-1775 гг. Львов, 1966. С. 159, 191-192.

5. Русский быт по воспоминаниям современников, XVIII век. Ч. 1. М., 1914. С. 315-316.

6. Соболева Г. Россия в песне. М.: Музыка, 1976. С. 90, 96, 98.

7. Электронный ресурc. URL: http://historic.ru/ (дата обращения: 24 ноября 2015 г.).

\section{References (transliterated):}

1. Bachinskaya N., Popova T. Russkoe narodnoe muzykal'noe tvorchestvo: khrestomatiya. Izd. 4-oe. M.: Muzyka, 1974. S. $122-126$.

2. Krest'yanskaya voina v Rossii v 1773-1775 godakh. Vosstanie Pugacheva. T. 2. L., 1966. S. 97, 103.

3. Pod znamenami Pugacheva. Chelyabinsk: Yuzhno-ural'skoe knizhnoe izd-vo, 1973. 195 s.

4. Rozner I. Kazachestvo v krest'yanskoi voine 1773-1775 gg. L'vov, 1966. S. 159, 191-192.

5. $\quad$ Russkii byt po vospominaniyam sovremennikov, XVIII vek. Ch. 1. M., 1914. S. 315-316.

6. Soboleva G. Rossiya v pesne. M.: Muzyka, 1976. S. 90, 96, 98.

7. Elektronnyy resurs. URL: http://historic.ru/ (data obrashcheniya: 24 noyabrya 2015 g.). 